\title{
Psychiatric comorbidity and suicide risk in patients with chronic migraine
}

This article was published in the following Dove Press journal:

Neuropsychiatric Disease and Treatment

25 March 2010

Number of times this article has been viewed

\author{
Maurizio Pompili ${ }^{1,2}$ \\ Gianluca Serafini' \\ Daniela Di Cosimo' \\ Giovanni Dominici' \\ Marco Innamorati' \\ David Lester ${ }^{3}$ \\ Alberto Forte ${ }^{1}$ \\ Nicoletta Girardi' \\ Sergio De Filippis ${ }^{4}$ \\ Roberto Tatarelli \\ Paolo Martelletti ${ }^{4}$ \\ 'Department of Neurosciences, \\ Mental Health and Sensory \\ Functions, Suicide Prevention Center, \\ Sant'Andrea Hospital, Sapienza \\ University of Rome, Rome, Italy; \\ ${ }^{2}$ McLean Hospital, Harvard Medical \\ School, Boston, Massachusetts, USA; \\ ${ }^{3}$ The Richard Stockton College of \\ New Jersey, USA; ${ }^{4}$ Department of \\ Medical Sciences, Second School \\ of Medicine, Sant'Andrea Hospital, \\ Sapienza University of Rome, \\ Rome, Italy
}

Correspondence: Maurizio Pompili Department of Psychiatry, Sant'Andrea Hospital, Sapienza University of Rome, 1035 Via di Grottarossa, Rome 00189, Italy

Tel +3906 33755675

Fax +3906 33755342

Email maurizio.pompili@uniromal.it
Abstract: The aim of this study was to explore the impact of mental illness among patients with migraine. We performed MedLine and PsycINFO searches from 1980 to 2008. Research has systematically documented a strong bidirectional association between migraine and psychiatric disorders. The relationship between migraine and psychopathology has often been clinically discussed rather than systematically studied. Future research should include sound methodologically-based studies focusing on the interplay of factors behind the relationship between migraine, suicide risk, and mental illness.

Keywords: headache, migraine, suicide*, psychiatric disorders

\section{Introduction}

The World Health Organization (WHO) has placed migraine 19th among all causes of disability worldwide (12th in women) according to metric years of healthy life lost to disability. ${ }^{1}$ In the US and Europe, migraine is the cause of an estimated $250,000,000$ lost days from work or school every year. In a study of 1,660 people in Belgium, the lifetime prevalence of migraine was $20.2 \%$ (95\% confidence intervals [CI]: $18.3 \%-22.2 \%$ ), significantly higher for women than for men, with the highest prevalence in the age group 35-44 years. On average, 10.6 lost working days due to migraine were reported per absentee and per year, on average 2.3 days for migraine sufferers, and 0.4 days for all employees. Migraine is estimated to account for about 1,154,336 lost working days each year in Flanders and Brussels. However, underreporting of symptoms, attacks, and sick leave days was estimated at about $50 \%$, depending on the time frame. Sixty-nine percent of the migraine sufferers use medication regularly. ${ }^{2}$ Clearly, the importance of headache disorders, particularly the primary forms, is established by their distribution worldwide, their duration (the majority being lifelong conditions), and their imposition of both disability and lifestyle restrictions on large numbers of people. For all these reasons, headache disorders should be a public health priority. ${ }^{3}$

Chronic daily headache (CDH), a group of disorders in which headache occurs 15 or more days per month for at least three months, ${ }^{4,5}$ such as chronic migraine (CM), chronic tension-type headache (CTTH), hemicrania continua, new daily persistent headache, and medication overuse headache $(\mathrm{MOH})$, is often comorbid with other conditions, ${ }^{4,5}$ such as depression (in up to $80 \%$ of migraine sufferers), anxiety (70\%), sleep complaints, slight (age/gender-adjusted odds ratio [OR] $=2.4[1.7-3.2]$ ), moderate $(\mathrm{OR}=3.6[2.6-5.0])$, and severe $(\mathrm{OR}=7.5[4.21-3.4]),{ }^{7}$ and fibromyalgia $(35 \%) .{ }^{8}$ 
Headache is one of the most common neurologic symptoms, and it often results in presentation in the emergency department (ED) ${ }^{9-12}$ In an Italian nationwide epidemiologic survey, headache was second only to cerebrovascular disorders (28\% versus $22 \%$ ) among the most common neurologic causes for attendance at an $\mathrm{ED} \cdot{ }^{13} \mathrm{In}$ a prospective study, diagnoses of ED patients reporting headache indicated primary headache disorders in the majority as opposed to secondary headaches attributed to underlying pathologies. ${ }^{14}$ Migraine (22\% of diagnoses) was the most frequent primary headache and twice as common as tension-type headache (TTH, 11\%), although $18 \%$ of cases were unspecified primary headache. Of the secondary headaches, $13 \%$ were serious or life-threatening conditions, including subarachnoid hemorrhage, cerebrovascular disease, and meningitis. ${ }^{15}$

Similar results have been found in pediatric ED attendance, $1 \%$ of which were attributed by an Italian survey to headache ${ }^{16}$ Primary headache was again diagnosed in most cases $(57 \%)$. However, over $90 \%$ of secondary headaches were caused by viral illnesses, but only $4 \%$ of children were in any immediate medical danger. ${ }^{16}$

Patients suffering from different types of headache typically complain of numerous accompanying symptoms (behavioral and somatic), which may be partially related to psychiatric comorbidity. ${ }^{17}$ Somatic symptoms have been demonstrated to be more common in patients with $\mathrm{CM},{ }^{18}$ especially for severe headaches with accompanying depression or anxiety. CM, moreover, should be considered as distinct from migraine with aura (MA), migraine without aura (MwoA), and migraine aura without headache (without a history of characteristic migraine headaches). Endicott reported that a high percentage of patients with major affective disorders had episodes with transient neurologic symptoms resembling the aura symptoms that can be seen in migraine patients. ${ }^{19}$

The diagnosis of headache does not always follow standard criteria and is complicated by the emergence of new terms and criteria, while the diagnosis of psychiatric disorders is based on a multiaxial coding system, ie, the DSM-IV. ${ }^{20}$ Axis I includes diagnoses of clinical disorders and other conditions that may be a focus of clinical attention, whereas Axis II includes diagnoses of personality disorders and mental retardation. Some Axis I and II psychiatric disorders are associated with headache. The prevalence and impact of these psychiatric disorders among headache patients have been the focus of several studies that have analyzed the relationship between migraine (and other types of headache) and major depression, anxiety, illicit drug abuse, nicotine dependence, and suicide attempts. ${ }^{21}$ Unfortunately, as noted by Silberstein et al, ${ }^{22}$ the relationship between headache and psychopathology has often been discussed only clinically rather than systematically studied. However, this relationship represents an important area for future headache research. Thus, the aim of the present study was to explore the prevalence and impact of mental illness among patients with migraine.

\section{Methods}

We performed careful MedLine and PsycINFO searches from 1980 to 2008. The following search terms were used: "headache" OR "migraine" and related terms, AND "psychiatric disorder", "psychiatric comorbidity", "substance abuse", "outcome", "suicid"* (which comprises suicide, suicidal, suicidality, and other suicide-related terms). In addition, each category was cross-referenced with the others using the MeSH method. We will review the historical context, pathophysiologic basis, epidemiology, risk factors, migraine, and the association with comorbid psychiatric disorders and substance abuse (include substance dependence/abuse in this section), suicide risk, and prognosis.

\section{Historical context}

Epidemiologic research has systematically documented a strong association between primary headaches and psychiatric disorders. ${ }^{23}$ Living described the occurrence of depressed mood, irritability, anxiety, memory, and attention deficit in patients with chronic headache in $1895 .{ }^{24} \mathrm{In}$ 1937, Wolf systematically studied these associations in patients with migraine who were not taking treatment for psychiatric illness. ${ }^{25} \mathrm{He}$ defined the "migraine personality" as a mixture of "personality features and reactions dominant in individuals with migraine" including "feelings of insecurity with tension manifested as inflexibility, conscientiousness, meticulousness, perfectionism, and resentment". ${ }^{26}$ This particular personality, characterized by anxious and depressive traits, is frequently found in subjects with $\mathrm{CM} .{ }^{27}$

In 1989, Endicott found that migraine was common among patients with major affective disorders and occurred with highest frequency in those with characteristics similar to DSM-IV bipolar patients. ${ }^{19}$ Wang et al studied the comorbidity between headache and depression in the elderly, which had rarely been the focus of research in the past. ${ }^{28}$ They were able to demonstrate that the risk of current depression was much greater in migraine sufferers than in nonmigraine patients. $^{28}$ 
More recently, several studies have portrayed this relationship as bidirectional. ${ }^{23}$ Migraine sufferers have a more than threefold risk of developing depression compared with nonmigraine patients, while depressed patients who have never suffered from migraine in the past have a more than threefold risk of developing migraine compared with nondepressed patients. The relationship is also specific because the presence of migraine or severe nonmigraine headache increases a patient's risk of developing depression or panic attack disorder, whereas the presence of depression or panic attack disorder is associated with a greater risk of developing migraine, but not severe nonmigraine headache. ${ }^{29}$

In 2008, Hung et al found that mental stress and depressive symptoms (anhedonia, decreased concentration, decreased libido, decreased energy, and sleep disorders) were the most common precipitating or aggravating factors for headache in patients with major depressive disorders. ${ }^{30}$ They suggested that headache was not a symptom of depression, but that headache and several mood and anxiety disorders are clinical entities that share some pathophysiologic bases.

\section{Pathophysiologic bases}

The importance of genetic factors in migraine ${ }^{31,32}$ and in mood disorders, ${ }^{33-35}$ raises the hypothesis of a mechanism common to both conditions, ${ }^{29,31}$ with the suggestion that similar neurochemical abnormalities might be implicated.$^{36}$ Recent studies of psychopathology and headache have demonstrated shared neuropathic mechanisms between migraine and affective disorders, ${ }^{37}$ involving limbic activation. ${ }^{38}$ Recent neuroscience research and experimental techniques such as positron emission tomography and functional magnetic resonance have shown that pain and mental suffering, such as depression, are related to the same brain regions (anterior cingulate, amygdala, orbitofrontal cortex, and temporal lobe). ${ }^{39}$ These data indicate that, even at the biologic level, pain and mental suffering share a common basis. Cady et al have suggested cosensitization of the sensory and affective components of head pain as a possible phenomenon. ${ }^{40}$ This hypothesis focuses on neuroplastic processes in corticolimbic structures, activated by both nociceptors and psychologic stimuli over a period of time, resulting in an integrated relationship between migraine (or pain) and psychiatric disorders in susceptible individuals. This susceptibility may be caused by a familial genetic variant of serotonergic dysfunction, alterations in monoamine systems, or channelopathy (a defect in calcium channels). ${ }^{32}$ Subsequent clinical development of these two pathologies, starting from a familial genetic variant of serotonergic dysfunction, initially involving pain regulation and cerebral perfusion with primarily onset of migraine, and then mood regulation, increases the risk for mood disorder onset. $^{21,41-43}$

Studying the relationship between subtypes of migraine headaches and affective disorders may be a way to explore further a possible common pathomechanism in both disorders. ${ }^{44}$ Disturbances in serotonergic systems are found in completed and attempted suicides, ${ }^{45}$ and the serotonergic systems are involved in the pathophysiology of both migraine and affective disorders. ${ }^{46,47}$

\section{Epidemiology}

Epidemiologic and clinical research consistently documents an association between depressive, bipolar, and anxiety disorders with migraine. ${ }^{48-50}$ Epidemiologic data have indicated a clinical association between migraine and mood disorders, with a lifetime prevalence of major depression three times higher among patients with migraine compared with patients without migraine. ${ }^{51}$ Affective disorders occur with at least a threefold greater frequency among recurrent headache patients than among the general population, and the prevalence increases in clinical populations, especially those with $\mathrm{CDH}^{48,52}$ In the case of CDH, a comorbid psychiatric disorder was present in $90 \%$ in a sample of 88 clinical patients. ${ }^{6}$

This comorbidity between $\mathrm{CDH}$ and psychiatric disorders seems to be more frequent in a particular type of patient. Taking into consideration different variables, it is possible to characterize a likely migraine person.

\section{Gender}

Women are significantly more likely to be affected than men. Women are four times more likely to develop migraine and two times more likely to develop major depression ${ }^{48}$ and, compared with men, often receive a diagnosis of both migraine (24\% versus $9 \%$ ) and major depression ( $24 \%$ versus $13 \%$ ) by age 30 , with the relative female risk increasing for migraine in late adolescence and for major depression after about age 20. In an epidemiologic study in Denmark, the gender distribution for both migraine aura without headache and MA was 1:2. ${ }^{53}$ However, another study reported that migraine aura without headache may be more common in men. ${ }^{54}$

\section{Age of onset}

MA is strongly associated with an early age of onset (OR: 11.4, age $<15$ years, OR: 5.6, age 15-24 years), and this variable explains the difference between the two migraine groups (migraine aura versus migraine aura without headache) better than the variables of suicide attempt (OR: 3.2, 
$P=0.13$, NS) or affective temperament (OR: $4.0, P=0.047) .{ }^{44}$ Migraine onset was earlier than mood disorder onset, and Franchini et al found no difference in migraine distribution according to the polarity of mood disorder, ${ }^{41}$ consistent with the findings of a previous study. ${ }^{51}$

\section{Family factors}

Mood disorder and migraine in first-degree relatives are significantly related to the risk of comorbidity. ${ }^{41}$

\section{Psychiatric disorders}

Endicott found that migraine was common among patients with major affective disorders and occurred with highest frequency in those with bipolar disorder II (51\% prevalence of migraine in patients with characteristics similar to bipolar II patients). ${ }^{19}$ In a questionnaire study of bipolar patients, Mahmood et al found that $26 \%$ fulfilled the criteria for a diagnosis of migraine. ${ }^{55}$

\section{Migraine subtype}

A higher prevalence of psychiatric comorbidity was observed in chronic forms of headache versus episodic forms, especially in CM patients. A high prevalence of sleep disorders, bowel disturbances, and fatigue frequently occurs in patients with chronic pain disorders, especially fibromyalgia. ${ }^{56}$ For episodic headaches, comorbid psychiatric disorders are more prevalent in migraine than in $\mathrm{TTH}^{56}$

\section{Migraine in children and adolescents}

Headache is common among children and adolescents. About $10 \%-30 \%$ of children and adolescents report weekly or daily headaches. ${ }^{57}$ Migraine occurs in $3 \%-15 \%$ of children, ${ }^{58,59}$ while $9 \%-33 \%$ of patients suffer from nonmigraine headache at least monthly. ${ }^{60}$

\section{Risk factors}

Many risk factors are independently involved in the development of psychiatric comorbidity in migraine patients and those with $\mathrm{CDH}$, among them genetic factors, higher depression scores, female gender, and chronic depression. ${ }^{61}$ Moreover, previous studies have reported a positive relationship between the frequency of headaches and the level of depression in headache patients (mood disorders were more frequent in patients who had chronic headache for more than five years). ${ }^{62}$ A report of two cases showed that a reduction in the severity of depression was associated with a reduction in headache severity. ${ }^{63}$
Both CM and CTTH share a surprisingly similar personality profile in women (along with an increased level of muscle tenderness) in association with psychiatric comorbidity, suggesting the involvement of these factors in the chronicity of headaches. ${ }^{64,65}$ An association between headache and certain personality traits or psychiatric disorders has also been reported in adults. ${ }^{31,66}$ In children, specific traits, such as rigidity and emotional inhibition, have been found among children with primary headache. ${ }^{67,68}$ TTH children were also more likely than migraine patients to have the temperament traits of shyness and irritability. ${ }^{69}$

Psychiatric comorbidity is associated not only with higher vulnerability to headache, but also with developing drug resistance and chronicity of primary headache. ${ }^{70}$

Several behavioral and psychologic risk factors are associated with the progression of headache from episodic to chronic and daily. ${ }^{71,72}$ And psychologic distress may play an even greater role in the transformation and chronicity of headache than does analgesic overuse/abuse.

A French study done in 2006 compared 30 simple migraineurs (SM) with 32 transformed migraineurs (TM) with medication overuse for impairment, emotional adjustment, and coping strategies. ${ }^{73} \mathrm{TM}$ with medication overuse is a complication of migraine characterized by an increase of crisis frequency and by a parallel increase of medication intake. Prevalence of TM with analgesic overuse in France seems to be as high as $3 \%$ in the general population. ${ }^{74}$

Lafittau et al reported that TM is associated with an increased disability concerning housework, leisure, work, and social activities. ${ }^{73}$ Statistical analysis shows higher $(P<0.001)$ Hospital Anxiety and Depression (HAD) scores for emotional distress (mean score $=32.2 \pm 10.9$ ) in TM than in SM (24.1 \pm 7.3$)$. TM were characterized by different coping strategies against pain, for example, the use of "dramatization", "distraction", and "praying", which are considered to be dysfunctional coping strategies, although SM used "reinterpretation", which is associated with better adjustment in term of disability and emotional distress. ${ }^{75}$

\section{Migraine and psychiatric disorders Migraine and Hamilton Rating Scale scores} The Hamilton Rating Scale, the most used clinical scale for assessing depression, includes headache in two items, while the Hamilton Rating Scale for anxiety includes headache in one item. There is research claiming that depression affects the onset and chronicity of primary headache. The average scores on the Hamilton Rating Scale for anxiety and depression were higher in headache sufferers than in healthy people. 
The frequency of headache attacks, history of headaches, and gender (women more than men) were correlated with scores on the Hamilton Rating Scale for both anxiety and depression. $^{76}$

\section{Psychiatric disorders and headache}

Psychiatric comorbidity was found more frequently in patients with chronic pain syndromes ${ }^{77}$ and recent research shows a strong relationship between psychiatric disorders and headache, both $\mathrm{CDH}$ and TTH. This relationship is complex and multifaceted, with existing studies confirming high rates of comorbidity between psychiatric disorders (especially depression and anxiety) and migraine and TTH, implicating comorbid psychiatric disorders as risk factors for headache progression and chronicity, and underscoring the need for assessment and treatment of relevant disorders. ${ }^{78}$ Depression was the psychiatric disorder most frequently associated with headache. ${ }^{23}$

The presence of migraine or severe nonmigraine headache increases a patient's risk of developing depression or panic attack disorder, whereas the presence of depression or panic attack disorder is associated with a greater risk of developing migraine, but not severe non-migraine headache. ${ }^{29}$ Merikangas et al in a prospective study, ${ }^{31}$ supported the hypothesis that anxiety induces or facilitates the onset of a primary headache, acting as a trigger for the subsequent development of a mood disorder such as depression. They assumed that migraine follows anxiety after several years, while it precedes the onset of depression by about four years. ${ }^{31}$

In a community-based study, high comorbidity with psychiatric disorders and suicidal risk was found in adolescents with CDH. The presence of migraine attacks, especially MA, was the major predictor for these associations. ${ }^{79}$ Subjects with migraine, anxiety, and chronic depression also had poor health-related quality of life. Migraine, specific phobias, and panic disorder were important and independent comorbidities predicting poor health-related quality of life..$^{30}$ These comorbidities have been identified in several epidemiologic studies, ${ }^{21,48,49,52}$ as well as in clinical studies of patients seeking treatment. ${ }^{52}$ The more common psychiatric conditions related to migraine are depression, bipolar disorders, anxiety (in particular, generalized anxiety disorders ${ }^{31}$ ), and somatoform disorders. These psychiatric comorbidities are more specifically related to migraine than to $\mathrm{TTH}$, both in children and in adults. ${ }^{31,80,81}$

In patients with episodic migraine, the presence of psychiatric disorders, such as anxiety or depression or both, is characterized by elevated muscle tenderness in the head, and even more in the neck, facilitating the evolution of the headache into the chronic form. ${ }^{64}$ In cases of episodic migraine without other psychiatric comorbidities, headache can be considered to be a manifestation of a somatoform disorder (including somatization disorder, conversion disorder, hypochondriasis, or pain disorder associated with psychologic factors), ${ }^{20}$ similar to other somatic complaints such as fatigue, loss of appetite, gastrointestinal symptoms, and urinary complaints.

It is important to distinguish between migraine with or without aura and migraine aura without headache. As demonstrated in one population-based epidemiologic study, ${ }^{31}$ MA was associated with multiple anxiety disorders, recurrent brief depression, and hypomania, whereas only the phobic and panic disorders were more frequent among patients suffering from MwoA. Patients with TTH did not differ from controls with respect to any of the affective or anxiety disorders. Oedegaard et al showed that a large number of patients presenting with major affective disorders have migraine aura without headache. The patients who had migraine aura without headache had a low level of affective temperament and a low probability of having made a suicide attempt, as well as a higher age of onset of migraine auras as compared with patients suffering from MA. ${ }^{44}$

Verri et al found an association between $\mathrm{CDH}$ and at least one psychiatric disorder in $90 \%$ of their cases, mainly generalized anxiety disorders in $69.3 \%$ cases, followed by major depression in $25 \%$ and dysthymia in $17 \%{ }^{6}$ Verri in 1998 and later Juang in 2000, in two different studies, affirmed that a long-standing major depressive disorder and chronic depression were the most common comorbidities among these patients, ${ }^{6,82}$ especially when the chronic headache syndrome had lasted for more than five years. However, Juang et al found that the frequency of any type of anxiety disorder was significantly higher in patients with CM than in those with $\mathrm{CTTH}^{82}$

In previous studies, the comorbidity between TTH and psychiatric disorders has been investigated only in clinical populations in which it has been showed that this association was more frequent in CTTH than in episodic TTH and that anxiety and mood disorders were higher in the CTTH patients than in controls, ${ }^{23,83}$ with significantly higher anxiety and depression scores in CTTH patients compared with headache-free controls. ${ }^{84,85}$ Moreover, in previous studies, among patients with episodic TTH, especially in CTTH, affective disorders were found to be more frequent. ${ }^{86}$ Of the three studies conducted in clinical samples, none reported 
any significant differences between migraine and TTH in terms of psychiatric comorbidity. ${ }^{85,87,88}$

Personality disorders have been less frequently examined in empirical headache research than have affective disorders. Torelli et al found that subjects with TTH had significantly higher scores than healthy controls on measures of automatic thoughts and alexithymia, and lower scores on assertiveness. ${ }^{89}$ Patients with CTTH had higher automatic thought scores than patients with episodic TTH. In another small sample study, using the Minnesota Multiphasic Personality Inventory II version (MMPI-2) with $\mathrm{CDH}$ patients, significantly high scores have been reported for the scales measuring hysteria, hypochondriasis, psychasthenia, depression, and social introversion. ${ }^{90}$

TTH patients have higher scores for the traits of emotionality and shyness, and lower for sociability, than patients with migraine. ${ }^{69}$ A higher emotionality score was also found among the parents and siblings of TTH children. ${ }^{69}$ High scores on emotionality and shyness can be considered to be symptoms of "behavioral inhibition". ${ }^{91,92}$ School-aged children who present with this trait are often irritable, shy, fearful, and introverted, and this temperament trait seems to increase the vulnerability to depressive and multiple anxiety disorders. ${ }^{93,94}$ Patients with TTH may have, as a group, more behavioral, emotional and temperament difficulties than children referred for migraine. ${ }^{69}$

This conclusion seems to be at odds with an epidemiologic study in Finland which found that psychiatric symptoms tended to be more strongly associated with migraine than with TTH, without any difference in anxiety symptoms. ${ }^{95}$ However, personality disorders are considered to be a complication for headache management, ${ }^{96-98}$ and significant headaches are a complaint of about $60 \%$ of patients with personality disorders presenting for acute treatment at hospital EDs. ${ }^{99}$

Tables 1 and 2 show details of representative studies of the prevalence of migraine in bipolar disorder as well as of studies demonstrating an association between migraine and depression.

\section{Suicide risk}

We have already described the shared pathophysiology of migraine, depression, and suicide. ${ }^{21,42,43}$ Suicide attempts seem to be more frequent in patients suffering from migraine than in the general population, especially in females and in patients having MA. ${ }^{100}$ These risk factors for suicidal behavior have also been found in the general population..$^{21,31,81,96}$ In contrast, $\mathrm{CDH}$ subtypes, headache frequencies, or medication overuse are not correlated with suicidal behavior. ${ }^{79}$
Table I Prevalence of migraine in bipolar disorder from representative studies ${ }^{100}$

\begin{tabular}{llll}
\hline Reference & Method & $\begin{array}{l}\text { Sample } \\
\text { size }(\mathbf{n})\end{array}$ & $\begin{array}{l}\text { Migraine } \\
\text { prevalence \% }\end{array}$ \\
\hline 127 & $\begin{array}{l}\text { Medical section of } \\
\text { DIGS }\end{array}$ & $327(\mathrm{~F}=186)$ & $21 . \mathrm{I}(\mathrm{F}=26.5)$ \\
128 & $\begin{array}{l}\text { Self-report of } \\
\text { headache }\end{array}$ & 100 & 49.0 \\
55 & $\begin{array}{l}\text { Self-report of IHS } \\
\text { migraine criteria }\end{array}$ & $81(\mathrm{~F}=37)$ & $25.9(\mathrm{~F}=27.0)$ \\
129 & $\begin{array}{l}\text { Diagnosis by } \\
\text { neurologist }\end{array}$ & 30 & 20.0 \\
51 & $\begin{array}{l}\text { Administered IHS } \\
\text { migraine criteria }\end{array}$ & 27 & $\begin{array}{l}\text { Bipolar I I3.0 } \\
\text { Bipolar II 77.0 } \\
130\end{array}$ \\
$\begin{array}{l}\text { Mother's report of } \\
\text { past diagnosis of } \\
\text { migraine }\end{array}$ & 21 & $28.6(\mathrm{~F}=0, \mathrm{M}=21)$ \\
\hline
\end{tabular}

Abbreviations: HIS, International Headache Society; DIGS, diagnostic interview for genetic studies.

Suicide attempts are associated with migraine, ${ }^{29}$ and MA also independently predicted a high suicidal risk (score $>10$ on the MINI Suicidality Module) in adolescents with $\mathrm{CDH}^{79}$ Wang et al investigated the relationship between migraine and suicidal ideation in a nonreferred sample of 3,963 adolescents (2,040 male and 1,923 female; mean age $14.0 \pm 0.9$ years; $93 \%$ of the target cohort). ${ }^{101}$ Suicidal ideation was reported in $8.5 \%$ of the sample. Compared with non-migraine subjects, subjects with migraine displayed a higher frequency of suicidal ideation (16.1\% versus $6.2 \%$ ), especially those with MA (23.9\%). Suicidal ideation was associated with higher headache frequency and headache-related disability but, after controlling for depression scores and sociodemographic characteristics, the association remained significant only for MA and high headache frequency. The relationship between MA and depression seems to be bidirectional. ${ }^{29}$

Hesdorffer et al found that the co-occurrence of major depression, suicide attempts, and MA increased the risk of unprovoked seizures more than the risk associated with either major depression or MA alone. ${ }^{102}$ The authors suggested that combinations of major depression, suicidality, MA, and seizure could constitute a cluster of conditions not hitherto described. In this model, it is possible, in their opinion, that the relationship between these conditions reflects a causal pathway where one brain dysfunction (eg, manifested by major depression) engenders other brain dysfunctions (eg, manifested by MA and unprovoked seizures). ${ }^{102}$

A history of MA, but not MwoA, is associated with increased frequency of suicidal ideation and suicide attempts in patients with major depression and with current or previous 
Table 2 Selected studies presenting the association between migraine and depression ${ }^{100}$

\begin{tabular}{|c|c|c|c|}
\hline Study & Method & $\begin{array}{l}\text { Migraine and } \\
\text { depression OR, } \\
95 \% \mathrm{CI}\end{array}$ & $\begin{array}{l}\text { Bidirectional } \\
\text { relationship } \\
\text { OR, } 95 \% \mathrm{CI}\end{array}$ \\
\hline \multicolumn{4}{|c|}{ Longitudinal studies } \\
\hline 48 & $\begin{array}{l}\text { IHS migraine } \\
\text { criteria }\end{array}$ & Not assessed & $\begin{array}{l}\text { New-onset migraine } \\
3.5,2.2-5.6 \\
\text { New-onset depression } \\
3.6,2.6-5.2\end{array}$ \\
\hline 29 & $\begin{array}{l}\text { IHS migraine } \\
\text { criteria }\end{array}$ & $3.5,2.6-4.6$ & $\begin{array}{l}\text { New-onset migraine } \\
2.8,2.2-3.5 \\
\text { New-onset depression } \\
2.4,1.8-3.0\end{array}$ \\
\hline 131 & $\begin{array}{l}\text { IHS migraine } \\
\text { criteria }\end{array}$ & Not assessed & $\begin{array}{l}\text { New-onset migraine } \\
3.4,1.4-8.7 \\
\text { New-onset depression } \\
5.8,2.7-12.3\end{array}$ \\
\hline \multicolumn{4}{|c|}{ Cross-sectional studies } \\
\hline 81 & $\begin{array}{l}\text { Diagnosis by } \\
\text { neurologist }\end{array}$ & $2.2, I . I-4.8$ & Not assessed \\
\hline 29 & $\begin{array}{l}\text { IHS migraine } \\
\text { criteria }\end{array}$ & $3.5,2.6-4.6$ & $\begin{array}{l}\text { New-onset migraine } \\
2.8,2.2-3.5 \\
\text { New-onset depression } \\
2.4,1.8-3.0\end{array}$ \\
\hline 113 & $\begin{array}{l}\text { IHS migraine } \\
\text { criteria }\end{array}$ & $3.1,2.0-4.4$ & $\begin{array}{l}\text { New-onset migraine } \\
0.68,0.02-2.0\end{array}$ \\
\hline 132 & $\begin{array}{l}\text { IHS migraine } \\
\text { criteria }\end{array}$ & $2.7,2.3-3.2$ & Not assessed \\
\hline 133 & $\begin{array}{l}\text { Diagnosis by } \\
\text { neurologist }\end{array}$ & $2.8,2.2-3.7$ & Not assessed \\
\hline 134 & $\begin{array}{l}\text { IHS migraine } \\
\text { criteria }\end{array}$ & $\begin{array}{l}\text { Strict migraine } 2.7, \\
2.2-3.3 \\
\text { Probable migraine } 1.9 \text {, } \\
\text { I.5-2.4 }\end{array}$ & Not assessed \\
\hline
\end{tabular}

Abbreviation: HIS, International Heachache Society.

affective episodes..$^{21,44,49,51,79}$ Oedegaard et al found that $17 \%$ of patients having migraine aura without headache $(n=18)$ had made a suicide attempt and had a lower frequency of the affective temperament as well as a higher age of onset of migraine aura compared with patients having MA $(n=57) .{ }^{44}$ However, the frequency of suicidal thoughts was approximately equal in the two groups. ${ }^{44}$

In 116 consecutive adult outpatients with a diagnosis of $\mathrm{CDH}$, De Filippis et al found that $28 \%$ had moderate to severe depression and $35 \%$ had severe hopelessness. ${ }^{103}$ Analyses also indicated that the quality of life, temperament, illness perception, and psychologic turmoil were associated. However, after hierarchical multivariate regression analysis, only the MINI suicidal intent score was associated with quality of life. It seems then that suicide risk may play a central role in affecting quality of life of patients with chronic headache. ${ }^{103}$
The pain associated with headache is itself a potential independent risk factor for suicide, particularly among those with chronic headache or multiple sources of coexisting pain. ${ }^{104}$ Individuals suffering from chronic pain may be particularly appropriate for suicide screening and intervention efforts. Innamorati et al proposed a new scale called the Italian Perceived Disability Scale, ${ }^{105}$ as a screening tool to identify comorbidity with emotional distress and disorders. This scale has proved able to predict suicidal intent and assess disability in patients with $\mathrm{CDH} .{ }^{105}$

\section{Substance dependence and abuse}

The impact of headache on the person and society is a public health issue. Recently, a study evaluated $51 \%$ of headache prevalence in Europe, of which 14\% of cases were migraine. About $4 \%-5 \%$ of the general population suffers from frequent, almost daily, headache attacks, and therefore $4 \%$ of the adult population is affected by chronic forms of headache, which constitutes an even more relevant problem in terms of health and social policies. ${ }^{106}$

Population studies estimate that patients who have lowfrequency episodic migraine or high-frequency episodic migraine will transition to $\mathrm{CM}$ at a rate of about $2.5 \%$ per year. ${ }^{107}$ Evers et al have reported that $\mathrm{MOH}$ was diagnosed in $8 \%$ of headache patients referred to a neurologic clinic, ${ }^{108}$ while Aaseth reported that the prevalence of $\mathrm{MOH}$ was 3.7\%. ${ }^{109}$

Psychiatric comorbidity is common in $\mathrm{MOH}$ patients and seems to play a role in the evolution of migraine to $\mathrm{MOH} .{ }^{110}$ Psychiatric comorbidity may be linked to medication overuse in patients suffering from migraine. ${ }^{111}$ Pakalnis et al found that headache patients had significantly more symptoms of anxiety, depression, and somatization compared with controls. ${ }^{110}$ Patients with $\mathrm{CDH}$ were at higher risk for emotional disorders, and medication overuse was a significant occurrence. Mitsikostas and Thomas replicated this finding, but only when $\mathrm{MOH}$ involved $\mathrm{CDH}^{85}$

Migraine is associated with substance abuse, nicotine dependence, and illicit drug use. ${ }^{12}$ Substance-related disorders have been examined in only three cross-sectional studies. Breslau et al found an increased risk of alcohol and drug abuse in migraine sufferers ${ }^{21}$ while Merikangas and the Epidemiologic Catchment Area Study did not, probably because substance abuse was highly comorbid with bipolar disorder in the Breslau study. ${ }^{21,31,113}$

In experimental studies, it has been shown that chronic use of analgesics may alter the functioning of the central 5-HT system. ${ }^{114} \mathrm{~A}$ comorbid psychiatric disorder may cause a stronger need to take analgesics in headache patients. ${ }^{115,116}$ 
Depressive patients may have decreased pain thresholds or may feel more unpleasant pain, resulting in analgesic overuse for the relief of their headache. Anxiety focused on the possibility of increasing pain may also play a role. ${ }^{117}$

\section{Prognosis}

Psychiatric comorbidity complicates the management of patients with headache, and the prognosis for headache treatment is poor. ${ }^{23,118-121}$ An eight-year followup study of 100 young adults with headache studied the relationship between psychiatric disorders at initial evaluation and headache status at followup. ${ }^{37}$ Patients with two or more psychiatric disorders at initial evaluation exhibited no improvement or deterioration in headache in $57 \%$ of the cases at followup; $29 \%$ of cases were improved and only $14 \%$ cases were headache-free. ${ }^{37}$ In contrast, patients with no or only one psychiatric disorder exhibited greater headache improvement eight years after the initial evaluation. Only $15 \%$ of cases were the same or worse, while $53 \%$ of cases were improved and $40 \%$ cases were headache-free. ${ }^{37}$ Migraine and depression independently exert a significant negative influence on quality of life. ${ }^{122}$

The results of studies on predictors of the outcome of $\mathrm{CDH}$ are conflicting. Some authors have reported that the predictors of persistent headaches include the presence of major depression, ${ }^{79}$ while others have reported that depression did not predict the persistence of $\mathrm{CDH} .{ }^{28}$ Depression is associated with increased personal suffering, mortality (suicide is the most common cause of death in patients with major depression), utilization of healthcare services, decreased functioning, and reduced quality of life. ${ }^{123-125}$ Other studies report that levels of emotional functioning and perception of stress, independent of the level of pain at baseline, were predictive of frequency, intensity, and duration of headaches. ${ }^{83,126}$ In depressed patients, headache in itself is a stressful event, and headache attacks are triggered or exacerbated by stress and depressed mood, producing a vicious cycle that is difficult to break.

\section{Conclusions}

Migraine is one of the major causes of disability and lost working days worldwide. ${ }^{1}$ Our analysis of the literature indicates a strong association between primary headaches and psychiatric disorders. ${ }^{23}$ The evidence of a possible link between chronic headache and psychiatric disorder is not a recent finding. Back in 1895, Living described the occurrence of depressed mood, irritability, and anxiety in patients with chronic headache. ${ }^{24}$ However, recently, research indicates that this association may be explained by shared neuropathic mechanisms between pain and affective disorders, ${ }^{37}$ perhaps involving limbic activation. ${ }^{38}$ Moreover, the literature shows an association between suicide attempts and migraine, ${ }^{29}$ and also indicates that MA may independently predict high suicidal risk in adolescent patients with $\mathrm{CDH} .{ }^{79}$

Our recent studies are consistent with these results, and indicate that patients with a diagnosis of $\mathrm{CDH}$ and migraine have severe hopelessness, ${ }^{103}$ and perceived disability. ${ }^{105}$ This evidence suggests that psychologic assessment is necessary in patients with $\mathrm{CM}$, and also that the presence of $\mathrm{CM}$ or headache has to be carefully monitored in patients with mental illness.

Selection of papers suitable for this study allowed inclusion only of articles published in English peer-reviewed journals, or articles published in non-English journals with an abstract in English. Included were those studies that added an original contribution to the literature. Clearly, articles included in this selective review may be only part of the relevant existing literature.

In conclusion, we are in agreement with authors who recommend future research with sound methodology focusing on the interplay of factors behind the relationship between migraine, suicide risk, and mental illness.

\section{Disclosures}

The authors report no conflicts of interest in this work.

\section{References}

1. World Health Organization. The World Health Report 2001. Geneva, Switzerland: World Health Organization; 2001.

2. Moens G, Johannik K, Verbeek C, Bulterys S. The prevalence and characteristics of migraine among the Belgian working population. Acta Neurol Belg. 2007;107(3):84-90.

3. Martelletti P, Steiner TJ, Bertolote JM, Dua T, Saraceno B. The definitive position of headache among the major public health challenges. An end to the slippery slope of disregard. J Headache Pain. 2007;8(3):149-151.

4. Dodick DW. Clinical practice. Chronic daily headache. $N$ Engl J Med. 2006;354(2):158-165.

5. Silberstein SD, Lipton RB, Sliwinski M. Classification of daily and near-daily headaches: Field trial of revised IHS criteria. Neurology. 1996;47(4):871-875.

6. Verri AP, Proietti Cecchini A, Galli C, Granella F, Sandrini G, Nappi G. Psychiatric comorbidity in chronic daily headache. Cephalalgia. 1998;18 Suppl 21:45-49.

7. Rains JC. Chronic headache and potentially modifiable risk factors: Screening and behavioral management of sleep disorders. Headache. 2008;48(1):32-39.

8. Peres MF, Young WB, Kaup AO, Zukerman E, Silberstein SD. Fibromyalgia is common in patients with transformed migraine. Neurology. 2001;57(7):1326-1328.

9. Locker T, Mason S, Rigby A. Headache management - are we doing enough? An observational study of patients presenting with headache to the emergency department. Emerg Med J. 2004;21(3):327-332. 
10. Stevenson RJ, Dutta D, MacWalter RS. The management of acute headache in adults in an acute admissions unit. Scott Med J. 1998;43(6):173-176.

11. Ramirez-Lassepas M, Espinosa CE, Cicero JJ, Johnston KL, Cipolle RJ, Barber DL. Predictors of intracranial pathologic findings in patients who seek emergency care because of headache. Arch Neurol. 1997;54(12):1506-1509.

12. Relja G, Granato A, Capozzoli F, et al. Non traumatic headache in the Emergency Department: A survey in the province of Trieste. $J$ Headache Pain. 2005;6:298-300.

13. de Falco FA, Sterzi R, Toso V, et al. The neurologist in the emergency department. An Italian nationwide epidemiological survey. Neurol Sci. 2008;29(2):67-75.

14. Toledo JB, Riverol M, Martinez-Vila E, Irimia P. Headache in the emergency department. An Sist Sanit Navar. 2008;31 Suppl 1:75-85. Spanish.

15. Locker TE, Thompson C, Rylance J, Mason SM. The utility of clinical features in patients presenting with nontraumatic headache: An investigation of adult patients attending an emergency department. Headache 2006;46(6):954-961.

16. Scagni P, Pagliero R. Headache in an Italian pediatric emergency department. J Headache Pain. 2008;9(2):83-87.

17. Mongini F, Ciccone G, Ibertis F, Negro C. Personality characteristics and accompanying symptoms in temporomandibular joint dysfunction, headache, and facial pain. J Orofac Pain. 2000;14(1):52-58.

18. Tietjen GE, Herial NA, Hardgrove J, Utley C, White L. Migraine comorbidity constellations. Headache. 2007;47(6):857-865.

19. Endicott NA. Psychophysiological correlates of 'bipolarity'. J Affect Disord. 1989;17(1):47-56.

20. American Psychiatric Association. Diagnostic and Statistical Manual of Mental Disorders. Washington, DC: American Psychiatric Association; 1994.

21. Breslau N, Davis GC, Andreski P. Migraine, psychiatric disorders, and suicide attempts: An epidemiologic study of young adults. Psychiatry Res. 1991;37(1):11-23.

22. Silberstein SD, Lipton RB, Breslau N. Migraine: Association with personality characteristics and psychopathology. Cephalalgia. 1995;15(5):358-69; discussion 336.

23. Puca F; the Italian Collaborative Group for the Study of Psychopathological Factors in Primary Headaches. Psychological and social stressors and psychiatric comorbidity in patients with migraine without aura from headache centers in Italy a comparison with tension-type. J Headache Pain. 2000;1:17-32.

24. Gentili C, Panicucci P, Guazzelli M. Psychiatric comorbidity and chronicisation in primary headache. J Headache Pain. 2005;6(4):338-340.

25. Wolff H. Personality features and reactions of subjects with migraine Arch Neurol Psychiatry. 1937;37:895-921.

26. Wolff H. Headache and Other Head Pain. NewYork, NY: Oxford University Press; 1948.

27. Catarci T, Clifford Rose F. Migraine and heredity. Pathol Biol. 1992;40(4):284-286.

28. Wang SJ, Liu HC, Fuh JL, Liu CY, Wang PN, Lu SR. Comorbidity of headaches and depression in the elderly. Pain. 1999;82(3):239-243.

29. Breslau N, Schultz LR, Stewart WF, Lipton RB, Lucia VC, Welch KM Headache and major depression: Is the association specific to migraine? Neurology. 2000;54(2):308-313.

30. Hung CI, Wang SJ, Yang CH, Liu CY. The impacts of migraine, anxiety disorders, and chronic depression on quality of life in psychiatric outpatients with major depressive disorder. J Psychosom Res. 2008;65(2):135-142.

31. Merikangas KR, Merikangas JR, Angst J. Headache syndromes and psychiatric disorders: Association and familial transmission. JPsychiatr Res. 1993;27(2):197-210.

32. Gardner K. The genetic basis of migraine: How much do we know? Can J Neurol Sci. 1999;26 Supp1 3:S37-S43.

33. Franchini L, Serretti A, Gasperini M, Smeraldi E. Familial concordance of fluvoxamine response as a tool for differentiating mood disorder pedigrees. J Psychiatr Res. 1998;32(5):255-259.
34. Serretti A, Franchini L, Gasperini M, Rampoldi R, Smeraldi E. Mode of inheritance in mood disorder families according to fluvoxamine response. Acta Psychiatr Scand. 1998;98(6):443-450.

35. Mahmood T, Silverstone T. Twin concordance for bipolar disorder and migraines. Am J Psychiatry. 2000;157(12):2057.

36. Fasmer OB, Oedegaard KJ. Migraine and psychiatric disorders. Tidsskr Nor Laegeforen. 2004;124(18):2350-2353. Norwegian.

37. Guidetti V, Galli F. Psychiatric comorbidity in chronic daily headache: Pathophysiology, etiology, and diagnosis. Curr Pain Headache Rep. 2002;6(6):492-497.

38. Rome HP Jr, Rome JD. Limbically augmented pain syndrome (LAPS): kindling, corticolimbic sensitization, and the convergence of affective and sensory symptoms in chronic pain disorders. Pain Med. 2000;1(1):7-23.

39. Chen AC. New perspectives in EEG/MEG brain mapping and PET/fMRI neuroimaging of human pain. Int $J$ Psychophysiol. 2001;42(2):147-159.

40. Cady R, Farmer K, Dexter JK, Schreiber C. Cosensitization of pain and psychiatric comorbidity in chronic daily headache. Curr Pain Headache Rep. 2005;9(1):47-52.

41. Franchini L, Bongiorno F, Dotoli D, Rainero I, Pinessi L, Smeraldi E. Migraine headache and mood disorders: A descriptive study in an outpatient psychiatric population. J Affect Disord. 2004;81(2):157-160.

42. Post RM, Silberstein SD. Shared mechanisms in affective illness, epilepsy, and migraine. Neurology. 1994;44(10 Suppl 7):S37-S47.

43. Pandey GN, Dwivedi Y, Rizavi HS, et al. Higher expression of serotonin 5-HT(2A) receptors in the postmortem brains of teenage suicide victims. Am J Psychiatry. 2002;159(3):419-429.

44. Oedegaard KJ, Angst J, Neckelmann D, Fasmer OB. Migraine aura without headache compared to migraine with aura in patients with affective disorders. J Headache Pain. 2005;6(5):378-386.

45. Lidberg L, Belfrage H, Bertilsson L, Evenden MM, Asberg M. Suicide attempts and impulse control disorder are related to low cerebrospinal fluid 5-HIAA in mentally disordered violent offenders. Acta Psychiatr Scand. 2000;101(5):395-402.

46. Hargreaves RJ, Shepheard SL. Pathophysiology of migraine - new insights. Can J Neurol Sci. 1999;26 Suppl 3:S12-S19.

47. Shiah IS, Ko HC, Lee JF, Lu RB. Platelet 5-HT and plasma MHPG levels in patients with bipolar I and bipolar II depressions and normal controls. J Affect Disord. 1999;52(1-3):101-110.

48. Breslau N, Merikangas K, Bowden CL. Comorbidity of migraine and major affective disorders. Neurology. 1994;44(10 Suppl 7): S17-S22.

49. Breslau N. Migraine, suicidal ideation, and suicide attempts. Neurology. 1992;42(2):392-395.

50. Breslau N, Rasmussen BK. The impact of migraine: Epidemiology, risk factors, and co-morbidities. Neurology. 2001;56(6 Suppl 1):S4-S12.

51. Fasmer OB, Oedegaard KJ. Clinical characteristics of patients with major affective disorders and comorbid migraine. World $\mathrm{J}$ Biol Psychiatry. 2001;2(3):149-155.

52. Merikangas KR, Stevens DE. Comorbidity of migraine and psychiatric disorders. Neurol Clin. 1997;15(1):115-123.

53. Russell MB, Rasmussen BK, Thorvaldsen P, Olesen J. Prevalence and sex-ratio of the subtypes of migraine. Int J Epidemiol. 1995;24(3): 612-618.

54. Alvarez WC. The migrainous scotoma as studied in 618 persons. Am J Ophthalmol. 1960;49:489-504.

55. Mahmood T, Romans S, Silverstone T. Prevalence of migraine in bipolar disorder. J Affect Disord. 1999;52(1-3):239-241.

56. Mongini F, Rota E, Deregibus A, et al. Accompanying symptoms and psychiatric comorbidity in migraine and tension-type headache patients. J Psychosom Res. 2006;61(4):447-451.

57. Egger HL, Angold A, Costello EJ. Headaches and psychopathology in children and adolescents. J Am Acad Child Adolesc Psychiatry. 1998;37(9):951-958.

58. Abu-Arefeh I, Russell G. Prevalence of headache and migraine in schoolchildren. BMJ. 1994;309(6957):765-769. 
59. Mortimer MJ, Kay J, Jaron A. Epidemiology of headache and childhood migraine in an urban general practice using ad hoc, Vahlquist and IHS criteria. Dev Med Child Neurol. 1992;34(12):1095-1101.

60. Egermark-Eriksson I. Prevalence of headache in Swedish schoolchildren. A questionnaire survey. Acta Paediatr Scand. 1982;71(1): 135-140.

61. Hung CI, Wang SJ, Hsu KH, Juang YY, Liu CY. Risk factors associated with migraine or chronic daily headache in outpatients with major depressive disorder. Acta Psychiatr Scand. 2005;111(4):310-315.

62. Chung MK, Kraybill DE. Headache: A marker of depression. J Fam Pract. 1990;31(4):360-364.

63. O'Reardon JP, Fontecha JF, Cristancho MA, Newman S. Unexpected reduction in migraine and psychogenic headaches following rTMS treatment for major depression: A report of two cases. CNS Spectr. 2007;12(12):921-925.

64. Mongini F, Ciccone G, Deregibus A, Ferrero L, Mongini T. Muscle tenderness in different headache types and its relation to anxiety and depression. Pain. 2004;112(1-2):59-64.

65. Mongini F, Rota E, Deregibus A, Mura F, Francia Germani A, Mongini T. A comparative analysis of personality profile and muscle tenderness between chronic migraine and chronic tension-type headache. Neurol Sci. 2005;26(4):203-207.

66. Waldie KE, Poulton R. Physical and psychological correlates of primary headache in young adulthood: A 26 year longitudinal study. J Neurol Neurosurg Psychiatry. 2002;72(1):86-92.

67. Traue HC. Inhibition of expression as a component of psychosomatic disorders. Z Psychosom Med Psychoanal. 1986;32(4):349-360.

68. Passchier J, Goudswaard P, Orlebeke JF, Verhage F. Migraine and defense mechanisms: Psychophysiological relationships in young females. Soc Sci Med. 1988;26(3):343-350.

69. Mazzone L, Vitiello B, Incorpora G, Mazzone D. Behavioural and temperamental characteristics of children and adolescents suffering from primary headache. Cephalalgia. 2006;26(2):194-201

70. Pietrini P, Guazzelli M. Life events in the course of chronic diseases: A psychological myth or a psycho-neuro-biochemical loop? Clin Exp Rheumatol. 1997;15(2):125-128.

71. Lipton RB, Pan J. Is migraine a progressive brain disease? JAMA. 2004;291(4):493-494.

72. Scher AI, Lipton RB, Stewart W. Risk factors for chronic daily headache. Curr Pain Headache Rep. 2002;6(6):486-491.

73. Lafittau M, Radat F, Irachabal S, Creac'h C. Headache and transformed migraine with medication overuse: What differences between disability, emotional distress and coping? Encephale. 2006;32(2 Pt 1):231-237.

74. Lanteri-Minet M. Pathophysiology of cluster headache. Rev Neurol. 2003;159(12):1113-1124

75. Riley JL 3rd, Robinson ME, Geisser ME. Empirical subgroups of the Coping Strategies Questionnaire-Revised: A multisample study. Clin $J$ Pain. 1999;15(2):111-116.

76. Hsu SC, Wang SJ, Liu CY, Juang YY, Yang CH, Hung CI. The impact of anxiety and migraine on quality of sleep in patients with major depressive disorder. Compr Psychiatry. 2009;50(2):151-157.

77. Polatin PB, Kinney RK, Gatchel RJ, Lillo E, Mayer TG. Psychiatric illness and chronic low-back pain. The mind and the spine - which goes first? Spine (Phila Pa 1976). 1993;18(1):66-71

78. Smitherman TA, Baskin SM. Headache secondary to psychiatric disorders. Curr Pain Headache Rep. 2008;12(4):305-310.

79. Wang SJ, Juang KD, Fuh JL, Lu SR. Psychiatric comorbidity and suicide risk in adolescents with chronic daily headache. Neurology. 2007;68(18):1468-1473.

80. Cuvellier JC. Management of chronic daily headache in children and adolescents. Rev Neurol. 2009;165(6-7):521-531.

81. Merikangas KR, Angst J, Isler H. Migraine and psychopathology. Results of the Zurich cohort study of young adults. Arch Gen Psychiatry. 1990;47(9):849-853.

82. Juang KD, Wang SJ, Fuh JL, Lu SR, Su TP. Comorbidity of depressive and anxiety disorders in chronic daily headache and its subtypes. Headache. 2000;40(10):818-823.
83. Penacoba-Puente C, Fernandez-de-Las-Penas C, Gonzalez-Gutierrez JL, Miangolarra-Page JC, Pareja JA. Interaction between anxiety, depression, quality of life and clinical parameters in chronic tension-type headache. Eur J Pain. 2008;12(7):886-894.

84. Holroyd KA, France JL, Nash JM, Hursey KG. Pain state as artifact in the psychological assessment of recurrent headache sufferers. Pain. 1993;53(2):229-235.

85. Mitsikostas DD, Thomas AM. Comorbidity of headache and depressive disorders. Cephalalgia. 1999;19(4):211-217.

86. Torelli P, Lambru G, Manzoni GC. Psychiatric comorbidity and headache: Clinical and therapeutical aspects. Neurol Sci. 2006;27 Suppl 2:S73-S76.

87. Marazziti D, Toni C, Pedri S, et al. Headache, panic disorder and depression: Comorbidity or a spectrum? Neuropsychobiology. 1995; 31(3):125-129.

88. Guidetti V, Galli F, Fabrizi P, et al. Headache and psychiatric comorbidity: Clinical aspects and outcome in an 8-year follow-up study. Cephalalgia. 1998;18(7):455-462.

89. Torelli P, Abrignani G, Castellini P, Lambru G, Manzoni GC. Human psyche and headache: Tension-type headache. Neurol Sci. 2008;29 Suppl 1:S93-S95.

90. Karakurum B, Soylu O, Karatas M, et al. Personality, depression, and anxiety as risk factors for chronic migraine. Int $J$ Neurosci. 2004;114(11):1391-1399.

91. Garcia-Coll C, Kagan J, Reznik JS. Behavioural inhibition in young children. Child Devel. 1984;55:1005-1019.

92. Kagan J, Reznick JS, Clarke C, Snidman N, Garcia-Coll C. Behavioural inhibition to the unfamiliar. Child Devel. 1984;55:2212-2225.

93. Goodyer IM, Ashby L, Altham PM, Vize C, Cooper PJ. Temperament and major depression in 11 to 16 year olds. J Child Psychol Psychiatry. 1993;34(8):1409-1423.

94. Kelvin RG, Goodyer IM, Altham PM. Temperament and psychopathology amongst siblings of probands with depressive and anxiety disorders. J Child Psychol Psychiatry. 1996;37(5):543-550.

95. Anttila P, Sourander A, Metsahonkala L, Aromaa M, Helenius H, Sillanpaa M. Psychiatric symptoms in children with primary headache. J Am Acad Child Adolesc Psychiatry. 2004;43(4):412-419.

96. Stewart WF, Linet MS, Celentano DD. Migraine headaches and panic attacks. Psychosom Med. 1989;51(5):559-569.

97. Sanchez-Roman S, Tellez-Zenteno JF, Zermeno-Phols F, et al. Personality in patients with migraine evaluated with the "Temperament and Character Inventory". J Headache Pain. 2007;8(2):94-104.

98. Abbate-Daga G, Fassino S, Lo Giudice R, et al. Anger, depression and personality dimensions in patients with migraine without aura. Psychother Psychosom. 2007;76(2):122-128.

99. Villani V, Bruti G, Mostardini C, et al. Migraine in the emergency department: A psychometric study of a migraine "repeaters" sample. $J$ Headache Pain. 2005;6(4):301-303.

100. Pompili M, Di Cosimo D, Innamorati M, Lester D, Tatarelli R, Martelletti P. Psychiatric comorbidity in patients with chronic daily headache and migraine: A selective overview including personality traits and suicide risk. J Headache Pain. 2009;10(4):283-290.

101. Wang SJ, Fuh JL, Juang KD, Lu SR. Migraine and suicidal ideation in adolescents aged 13 to 15 years. Neurology. 2009;72(13):1146-1152.

102. Hesdorffer DC, Ludvigsson P, Hauser WA, Olafsson E, Kjartansson O. Co-occurrence of major depression or suicide attempt with migraine with aura and risk for unprovoked seizure. Epilepsy Res. 2007;75(2-3): 220-223.

103. De Filippis S, Erbuto D, Gentili F, et al. Mental turmoil, suicide risk, illness perception, and temperament, and their impact on quality of life in chronic daily headache. J Headache Pain. 2008;9(6):349-357.

104. Ilgen MA, Zivin K, McCammon RJ, Valenstein M. Pain and suicidal thoughts, plans and attempts in the United States. Gen Hosp Psychiatry. 2008;30(6):521-527.

105. Innamorati M, Pompili M, De Filippis $S$, et al. The validation of the Italian Perceived Disability Scale (IPDS) in chronic daily headache sufferers. J Headache Pain. 2009;10(1):21-26. 
106. de Filippis S, Salvatori E, Farinelli I, Coloprisco G, Martelletti P. Chronic daily headache and medication overuse headache: Clinical read-outs and rehabilitation procedures. Clin Ter. 2007;158(4): 343-347.

107. Lipton RB. Tracing transformation: Chronic migraine classification, progression, and epidemiology. Neurology. 2009;72(5 Suppl):S3-S7.

108. Evers S, Suhr B, Bauer B, Grotemeyer KH, Husstedt IW. A retrospective long-term analysis of the epidemiology and features of druginduced headache. J Neurol. 1999;246(9):802-809.

109. Aaseth K, Grande RB, Lundqvist C, Russell MB. What is chronic headache in the general population? The Akershus study of chronic headache. Acta Neurol Scand Suppl. 2009;189:30-32.

110. Pakalnis A, Butz C, Splaingard D, Kring D, Fong J. Emotional problems and prevalence of medication overuse in pediatric chronic daily headache. J Child Neurol. 2007;22(12):1356-1359.

111. Kaji Y, Hirata K. Characteristics of mood disorders in Japanese patients with medication-overuse headache. Intern Med. 2009; 48(12):981-986.

112. Breslau N, Davis GC. Migraine, physical health and psychiatric disorder: A prospective epidemiologic study in young adults. J Psychiatr Res. 1993;27(2):211-221.

113. Swartz KL, Pratt LA, Armenian HK, Lee LC, Eaton WW. Mental disorders and the incidence of migraine headaches in a community sample: Results from the Baltimore Epidemiologic Catchment area follow-up study. Arch Gen Psychiatry. 2000;57(10):945-950.

114. Sandrini M, Vitale G, Pini LA, Sternieri E, Bertolini A. Effects of chronic treatment with phenazone on the hot-plate test and $[3 \mathrm{H}]$ serotonin binding sites in pons and cortex membranes of the rat. Pharmacology. 1993;47(2):84-90.

115. Fishbain DA. Approaches to treatment decisions for psychiatric comorbidity in the management of the chronic pain patient. Med Clin North Am. 1999;83(3):737-760, vii.

116. Katon WJ. Depression in patients with inflammatory bowel disease. J Clin Psychiatry. 1997;58(Suppl 1):20-23.

117. Nisbett RE, Schachter S. Cognitive manipulation of pain. J Exp Soc Psychol. 1966;2:227-236.

118. Penzien DB, Peatfield R, Lipchik GL. Headache in patients with co-morbid psychiatric disease. In: Olesen J, Goadsby P, Ramadan N, Tfelt-Hansen P, Welsch K editors. The Headaches. Philadelphia, PA: Lippincott, Williams \& Wilkins; 2005.

119. Lake AE 3rd. Behavioral and nonpharmacologic treatments of headache. Med Clin North Am. 2001;85(4):1055-1075.

120. Lipchik GL, Rains J. Psychiatric and psychologic factors in headache. In: Loder E, Marcus D editors. Migraine in Women. Hamilton, Ontario: Decker; 2004. p. 144-164.
121. Lipchik GL, Penzien DB. Psychiatric comorbidities in patients with headache. Sem Pain Med. 2004;2:93-105.

122. Lipton RB, Hamelsky SW, Kolodner KB, Steiner TJ, Stewart WF. Migraine, quality of life, and depression: A population-based casecontrol study. Neurology. 2000;55(5):629-635.

123. Rovner BW, German PS, Brant LJ, Clark R, Burton L, Folstein MF. Depression and mortality in nursing homes. JAMA. 1991;265(8): 993-996.

124. Ormel J, VonKorff M, Ustun TB, Pini S, Korten A, Oldehinkel T. Common mental disorders and disability across cultures. Results from the WHO Collaborative Study on Psychological Problems in General Health Care. JAMA. 1994;272(22):1741-1748.

125. Simon GE, VonKorff M, Barlow W. Health care costs of primary care patients with recognized depression. Arch Gen Psychiatry. 1995;52(10):850-856.

126. Labbe EE, Murphy L, O’Brien C. Psychosocial factors and prediction of headaches in college adults. Headache. 1997;37(1):1-5.

127. Blehar MC, DePaulo JR Jr, Gershon ES, Reich T, Simpson SG, Nurnberger JI Jr. Women with bipolar disorder: Findings from the NIMH Genetics Initiative sample. Psychopharmacol Bull. 1998;34(3): 239-243.

128. Cassidy WL, Flanagan NB. Clinical observations in manic-depressive disease. JAMA. 1957;164:1535-1546.

129. Marchesi C, De Ferri A, Petrolini N, et al. Prevalence of migraine and muscle tension headache in depressive disorders. J Affect Disord. 1989;16(1):33-36.

130. Younes RP, DeLong GR, Neiman G, Rosner B. Manic-depressive illness in children: Treatment with lithium carbonate. J Child Neurol. 1986;1(4):364-368.

131. Breslau N, Lipton RB, Stewart WF, Schultz LR, Welch KM. Comorbidity of migraine and depression: Investigating potential etiology and prognosis. Neurology. 2003;60(8):1308-1312.

132. Zwart JA, Dyb G, Hagen K, et al. Depression and anxiety disorders associated with headache frequency. The Nord-Trondelag Health Study. Eur J Neurol. 2003;10(2):147-152.

133. McWilliams LA, Goodwin RD, Cox BJ. Depression and anxiety associated with three pain conditions: Results from a nationally representative sample. Pain. 2004;111(1-2):77-83.

134. Patel NV, Bigal ME, Kolodner KB, Leotta C, Lafata JE, Lipton RB Prevalence and impact of migraine and probable migraine in a health plan. Neurology. 2004;63(8):1432-1438
Neuropsychiatric Disease and Treatment

\section{Publish your work in this journal}

Neuropsychiatric Disease and Treatment is an international, peerreviewed journal of clinical therapeutics and pharmacology focusing on concise rapid reporting of clinical or pre-clinical studies on a range of neuropsychiatric and neurological disorders. This journal is indexed on PubMed Central, the 'PsycINFO' database and CAS, and is the official

\section{Dovepress}

journal of The International Neuropsychiatric Association (INA). The manuscript management system is completely online and includes a very quick and fair peer-review system, which is all easy to use. Visit http://www.dovepress.com/testimonials.php to read real quotes from published authors. 